\title{
Influence of the socieconomic level on the temporal resolution hearing skills in adults
}

\author{
Livia Barbosa Aguiar ${ }^{1}$ \\ https://orcid.org/0000-0003-2998-6080 \\ Ellen Karoline de Souza ${ }^{1}$ \\ https://orcid.org/0000-0002-9673-6412 \\ Carolina Karla de Souza Evangelista ${ }^{1}$ \\ https://orcid.org/0000-0001-8325-509X \\ Aryelly Dayane da Silva Nunes ${ }^{2}$ \\ https://orcid.org/0000-0002-3814-2675 \\ Kaio Ramon de Aguiar Lima ${ }^{3}$ \\ https://orcid.org/0000-0002-7220-3849 \\ Sheila Andreoli Balen ${ }^{4}$ \\ https://orcid.org/0000-0003-1353-4362
}

\begin{abstract}
Universidade Federal do Rio Grande do Norte - UFRN, Curso de Fonoaudiologia, Laboratório de Inovação Tecnológica em Saúde/ Hospital Universitário Onofre Lopes, Natal, Rio Grande do Norte, Brasil.

2 Universidade Federal do Rio Grande do Norte - UFRN, Programa de Pós-Graduação em Saúde Coletiva, Laboratório de Inovação Tecnológica em Saúde/ Hospital Universitário Onofre Lopes, Natal, Rio Grande do Norte, Brasil.

${ }^{3}$ Universidade Federal do Rio Grande do Norte, Laboratório de Inovação Tecnológica em Saúde/ Hospital Universitário Onofre Lopes, Natal, Rio Grande do Norte, Brasil.

Universidade Federal do Rio Grande do Norte, Departamento de Fonoaudiologia, Laboratório de Inovação Tecnológica em Saúde/ Hospital Universitário Onofre Lopes, Natal, Rio Grande do Norte, Brasil.
\end{abstract}

Scientific Initiation Scholarship Program, Federal University of Rio Grande do Norte.

Conflict of interests: Nonexistent

(c)
Received on: January 28, 2019
Accepted on: August 30, 2019
Corresponding address:
Sheila Andreoli Balen
Rua Desembargador Hemetério Fernandes,
n¹162, Edifício José de Almeida,
apto:102, Bairro: Tirol
CEP: 59015-110 - Natal,
Rio Grande do Norte, Brasil
E-mail: sheilabalen@gmail.com

\section{ABSTRACT}

Objective: to investigate the influence of the socioeconomic level on the temporal resolution auditory ability of adults.

Methods: the sample consisted of 48 subjects aged 18 to 50 years, divided into three groups: G1, 11 subjects at level A; G2, 19 in B1 and B2 and G3, 18 in C1, C2, D and E. All subjects presented responses in $20 \mathrm{~dB} \mathrm{HL}$ in frequencies of 500 to $4000 \mathrm{~Hz}$, during audiometric screening, type A tympanometry, presence of contralateral and ipsilateral acoustic reflexes, no neurological, psychiatric and / or psychological changes diagnosed; without audiological and / or otological complaints and with performance above 95\% in the dichotic digit test. The Random Gap Detection and Gap-in-noise tests were performed. The Shapiro-Wilk test for normality analysis and the Kruskall Wallis test for socioeconomic stratum analysis, were used, both with $5 \%$ significance.

Results: there were statistically significant differences between the groups in the Random Gap Detection in the frequency of $500 \mathrm{~Hz}$ and in the average of the frequencies, as a function of the socioeconomic level, the same not being observed in the Gap-in-noise.

Conclusions: it is suggested that the socioeconomic level be taken into account in the analysis of the Random Gap Detection test.

Keywords: Hearing Tests; Social Class; Adult; Auditory Perception 


\section{INTRODUCTION}

The central auditory processing (CAP) assessment has become an essential clinical practice for its contribution to audiological diagnosis in all age groups. It contributes to the differential diagnosis of peripheral and central alterations ${ }^{1}$ and to the process of speech rehabilitation.

Among the auditory skills assessed in the CAP, temporal resolution is described as the ability to detect small changes in stimuli over time, which is fundamental for speech recognition ${ }^{2}$. In a study ${ }^{3}$ it was found that changes in temporal resolution may result in difficulties in identifying small acoustic variations in speech and, consequently, difficulty in producing speech sounds or interpreting the heard message.

The pure-tone audiogram provides information about hearing sensitivity in a selected frequency range, providing information about "hearing". Although essential for audiology, it has limitations, especially in the case of central auditory pathway involvement. Therefore, advances in auditory neuroscience highlight the considerably greater role of the central auditory nervous system (CANS) in auditory disorders and the like, thus requiring more specific evaluations of these structures ${ }^{4}$.

In view of this need, gap detection tests have been developed to assess temporal resolution. The Gaps-InNoise (GIN) test measures the detection of gaps in white noise (WN) $(\mathrm{RGDT})^{6}$ consists of pure-tone pairs with silent intervals between the two tones, ranging from 0 to $40 \mathrm{~ms}$, or in the expanded version, from 50 to $300 \mathrm{~ms}$.

These two tests assess the temporal resolution ability differently, as verified from the distinct tasks performed by the subject in each test. The GIN test provides gap detection values, and the RGDT partly reflects auditory fusion. Moreover, the two tests differ in aspects of presentation mode (monaural vs. binaural), type of stimuli (noise vs. tones), response mode (motor vs. verbal), response task (motor vs. count) ${ }^{5-7}$, and total number of gap presentations (60 noise gaps vs. 45 tones) $)^{5}$.

Studies with adult subjects showed the good sensitivity, specificity, and reproducibility of the GIN test $^{5}$ and normative standards for adult individuals similar,9 to what was found in the original study, with American individuals ${ }^{4}$, and in another study with Polish individuals ${ }^{10}$. Regarding the RGDT, a study ${ }^{9}$ with adult individuals between 18 and 29 years of age found a mean of $10.09 \mathrm{~ms}$. Two other studies found, respectively, a mean duration threshold of 6.5 and $6.0 \mathrm{~ms}$ in the RGDT in typical adult individuals ${ }^{11,12}$.

While there is a large literature on the RGDT and the GIN test, the analysis of the influence of socioeconomic status was not evidenced in studies with typical individuals. A study ${ }^{13}$ with children showed that there is influence of socioeconomic status on temporal resolution in this age group. In addition, another study with the elderly population found influences of socioeconomic and cultural status on the results of the RGDT, suggesting that more caution should be exercised in the use of this test in the population, as the elderly who responded significantly better were those from the most favored classes. On the other hand, the group in the most disadvantaged class, in addition to poorer results, had difficulties understanding the tests, and the practice track had to be repeated. All individuals performed the test, and those of the upper class presented values within normal range, obtaining results less than $20 \mathrm{~ms}^{14}$.

Evidence was also found that, in auditory processing tests, individuals with low-medium cultural and socioeconomic status have a greater gap in the assessed auditory skills. This result is justified by the fact that the CAP depends on the amount of environmental stimulation, and that poor socioeconomic conditions cause these auditory skills to decay ${ }^{14,15}$.

There is a need for studies on the socioeconomic consequences in adults, especially those addressing normative standards, generating reference values for the audiological clinic. Thus, the aim of this study was to verify the influence of socioeconomic status on auditory temporal resolution (RGDT and GIN test) in adults.

\section{METHODS}

This is a prospective and cross-sectional study. It was approved by the Research Ethics Committee of the Onofre Lopes University Hospital (2.048.980). All subjects signed the Informed Consent Form.The non-probabilistic sample consisted of 48 subjects aged 18 to 50 years $(X=25.40 \pm 7.36)$ classified into three groups according to socioeconomic status: Group 1,11 subjects of socioeconomic status A; Group 2, 19 subjects of socioeconomic status B1 and B2; and Group 3, 18 subjects of socioeconomic status C1, C2, $D-E^{16}$.

The questionnaire of the Brazilian Association of Research Companies (ABEP) ${ }^{16}$ was used to characterize the subjects according to socioeconomic status. 
For this purpose, predetermined values were used in the questionnaire, in order to score the number of objects that the individual has at home, based on the Brazilian National Household Sample Survey ${ }^{17}$, the education level of the head of household, and access to public services (running water and paved streets). From the overall score, the individual is categorized into one of the proposed classes - A, B1, B2, C1, C2, and D-E. In this study, the individuals were recategorized by joining classes B1 and B2, as well as classes C1, C2, D, and E, in order to classify three socioeconomic statuses that were used in the analysis of the results: Group 1: status A with scores between 38 and 44; Group 2: status B with scores between 23 and 37; and Group 3: status C with scores from 0 to 22 points.

Initially, medical history was obtained for information about audiological complaints, medication use, lifestyle, and pathophysiological history of the subjects. Then, an external acoustic meatus inspection was performed with a Heidjiß otoscope. The audiometric screening was performed in a sound-treated acoustic booth, using the Madsen Itera II audiometer, with TDH-39p Telephonics earphones with the scanning technique with responses at $20 \mathrm{~dB}$ HL bilaterally at 500 to $4000 \mathrm{~Hz}$ bilaterally. For acoustic-immittance measurements (AIM), the Interacoustics AT 235 impedanciometer was used. The presence of a type A tympanogram in both ears and ipsi- and contralateral acoustic reflexes present at frequencies of $500,1000,2000$, and $4000 \mathrm{~Hz}$ were adopted as normality criteria.

We included subjects who presented, during screening, hearing thresholds equal to or lower than 20 $\mathrm{dB} \mathrm{HL}$ at frequencies from $500 \mathrm{~Hz}$ to $4000 \mathrm{~Hz}$, with type A tympanograms, whose characteristics are pressure between -100 and $+100 \mathrm{daPa}$ and compliance from 0.3 to $1.6 \mathrm{ml}^{18}$, indicating normality of the tympanicossicular system. The subjects should have absence of diagnosed neurological, psychiatric, and/or psychological alterations, of audiological and/or otological complaints, and should have a score equal to or higher than $95 \%$ in the dichotic digit test (binaural integration task $)^{19}$, applied as a CAP screening procedure. Six subjects were excluded, two of them because they had a neurological history, one because he/she did not perform the dichotic digit test, and three because they did not score $95 \%$ or higher on the dichotic digit test.

The RGDT ${ }^{6}$ consists of pure-tone pairs at frequencies of $500,1000,2000$, and $4000 \mathrm{~Hz}$, with intervals between the two tones ranging from 0 to $40 \mathrm{~ms}$ (RGDT) and from 50 to 300ms (RGDT - Expanded). This test was initially presented with a practice track at $50 \mathrm{~dB} \mathrm{SL}$ in binaural condition. Subjects were instructed without headphones to respond verbally if they heard one or two tones, for the detection of silent intervals with values less than or equal to $40 \mathrm{~ms}$. Once the understanding of the procedure was confirmed, the test was conducted at frequencies of 500, 1000, 2000, and $4000 \mathrm{~Hz}$. In cases of non-identification of $40 \mathrm{~ms}$ intervals, the RGDT-Expanded was used. The analysis of RGDT results was performed based on the shortest interval from which the individual began to identify the presence of both stimuli. They were individually pointed out for each frequency from 500 to $4000 \mathrm{~Hz}$ and then the mean results of the four frequencies were established. The following normative values are expected: $6.78 \pm 5.93$ at $500 \mathrm{~Hz} ; 6.07 \pm 4.25$ at $1000 \mathrm{~Hz} ; 7.07 \pm$ 4.37 at $2000 \mathrm{~Hz} ; 7.07 \pm 4.37$ at $4000 \mathrm{~Hz}$ and means of the four frequencies of $6.5 \pm 3.25^{6}$.

The GIN test consists of 6-second-stimuli of WN, interspersed with randomly presented silent intervals (gaps) lasting 2 to $20 \mathrm{~ms}$. After verbal instruction on the test task, a practice track of 10 segments of noise with gaps from 2 to $20 \mathrm{~ms}$ gaps was applied. If the task was understood, the tests were started with a total of 60 gaps (6 gaps of each of the following intervals: $2,3,4,5,6,8,10,12,15$, and 20ms). As a response method, subjects were instructed to push a button when detecting the intervals between noises. The temporal acuity threshold by ear was established for the shortest noise interval that was detected in four of the six randomized presentations ${ }^{5}$.

The research procedures were applied in a single session, and the initial order of each test and ear to be evaluated by the GIN test were randomized. The RGDT was always performed in the following order: 500, 1000,2000 , and $4000 \mathrm{~Hz}$. After the tests were applied, the results were tabulated in an Excel spreadsheet and statistically analyzed using the SPSS 22.0 program. For normality analysis, the Shapiro-Wilk test was used and no normal distribution was evidenced. The KruskalWallis test was applied to compare whether the performance on the GIN test and the RGDT varied between established socioeconomic status categories. A significance level of $5 \%$ was adopted. 


\section{RESULTS}

Table 1 shows the characterization of the sample of 48 subjects divided into socioeconomic groups according to sex and age group. There was a predominance of females and of the 18-31-year age group in the sample studied.

Table 2 shows the means of gap detection thresholds of subjects for the RGDT test by frequency according to socioeconomic status. Statistically significant difference was observed at $500 \mathrm{~Hz}$, intergroups, according to the Kruskall Wallis test.

Table 3 shows that there is no difference in performance on the GIN test according to socioeconomic status by ear.

Table 1. Characterization of the sample regarding sex and age according to socioeconomic status

\begin{tabular}{ccccc}
\hline & $\begin{array}{c}\text { Group 1 } \\
\mathbf{N = 1 1}\end{array}$ & $\begin{array}{c}\text { Group 2 } \\
\mathbf{N = 1 9}\end{array}$ & $\begin{array}{c}\text { Group 3 } \\
\mathbf{N = 1 8}\end{array}$ & $\begin{array}{c}\text { TOTAL } \\
\mathbf{N}=\mathbf{4 8}\end{array}$ \\
\hline Sex & & & & \\
Females & $4(36.36 \%)$ & $12(63.15 \%)$ & $15(83.34 \%)$ & $31(64.58 \%)$ \\
Males & $7(63.64 \%)$ & $7(36.85 \%)$ & $3(16.66 \%)$ & $17(35.42 \%)$ \\
\hline Age (mean \pm sd) & $29.45 \pm 4.95$ & $27.47 \pm 9.18$ & $23.78 \pm 6.71$ & $25.40 \pm 7.36$ \\
$18 \mid-30$ & $10(90.90 \%)$ & $15(78.94 \%)$ & $16(88.88 \%)$ & $41(85.42 \%)$ \\
$31 \mid-50$ & $1(9.10 \%)$ & $4(21.06 \%)$ & $2(11.12 \%)$ & $7(14.58 \%)$ \\
\hline
\end{tabular}

Table 2. Descriptive and inferential analysis of the sample in the Random Gap Detection Test in ms by frequency, according to socioeconomic status

\begin{tabular}{|c|c|c|c|c|c|}
\hline Socioeconomi & DT by frequency & Group 1 & Group 2 & Group 3 & $p$ value \\
\hline \multirow{4}{*}{$500 \mathrm{~Hz}$} & Mean \pm sd & $4.54 \pm 3.04$ & $14.26 \pm 14.57$ & $21.72 \pm 18.38$ & \multirow{4}{*}{$0.008^{*}$} \\
\hline & Q1 & 2.00 & 5.00 & 5.00 & \\
\hline & Median & 5.00 & 10.00 & 15.00 & \\
\hline & Q3 & 5.00 & 15.00 & 32.50 & \\
\hline \multirow{4}{*}{$1000 \mathrm{~Hz}$} & Mean \pm sd & $17.63 \pm 15.76$ & $14.10 \pm 15.78$ & $28.55 \pm 38.90$ & \multirow{4}{*}{0.457} \\
\hline & Q1 & 5.00 & 5.00 & 5.00 & \\
\hline & Median & 15.00 & 5.00 & 10.00 & \\
\hline & Q3 & 40.00 & 15.00 & 40.00 & \\
\hline \multirow{4}{*}{$2000 \mathrm{~Hz}$} & Mean \pm sd & $7.36 \pm 6.63$ & $12.68 \pm 12.86$ & $20.55 \pm 22.35$ & \multirow{4}{*}{0.066} \\
\hline & Q1 & 2.00 & 5.00 & 5.00 & \\
\hline & Median & 5.00 & 5.00 & 10.00 & \\
\hline & Q3 & 10.00 & 15.00 & 25.00 & \\
\hline \multirow{4}{*}{$4000 \mathrm{~Hz}$} & Mean \pm sd & $8.36 \pm 6.59$ & $10.58 \pm 11.69$ & $20.83 \pm 34.13$ & \multirow{4}{*}{0.266} \\
\hline & Q1 & 5.00 & 5.00 & 5.00 & \\
\hline & Median & 5.00 & 5.00 & 10.00 & \\
\hline & Q3 & 10.00 & 10.00 & 20.00 & \\
\hline \multirow{4}{*}{$\begin{array}{l}\text { Mean of the } \\
\text { frequencies }\end{array}$} & Mean \pm sd & $9.47 \pm 6.50$ & $12.90 \pm 11.22$ & $22.91 \pm 24.09$ & \multirow{4}{*}{$0.032^{*}$} \\
\hline & Q1 & 4.25 & 5.00 & 10.00 & \\
\hline & Median & 8.50 & 11.25 & 15.00 & \\
\hline & Q3 & 15.00 & 18.00 & 25.37 & \\
\hline
\end{tabular}

Caption: Group 1 subjects of socioeconomic status A; Group 2, subjects of socioeconomic status B1 and B2; and Group 3, subjects of socioeconomic status C1, C2, $D$ - $\mathrm{E}^{16}$. Q1 - First quartile; Q3 - Third quartile. RGDT - Random gap detection test.

* Kruskal Wallis test in intergroup analysis, $p<0.05$. 
Table 3. Descriptive and inferential statistical analysis of the sample in the Gaps-In-Noise (GIN) Test in ms of each ear assessed, according to socioeconomic status

\begin{tabular}{cccccc}
\hline \multicolumn{2}{c}{ Socioeconomic status/GIN by ear } & Group 1 & Group 2 & Group 3 & p value \\
\hline \multirow{3}{*}{ GIN RE } & Mean \pm sd & $7.36 \pm 2.06$ & $7.10 \pm 2.13$ & $7.22 \pm 2.39$ & \\
& Q1 & 5.00 & 5.00 & 10.00 & 0.905 \\
& Median & 8.00 & 8.00 & 15.00 & \\
\hline \multirow{3}{*}{ GIN LE } & Q3 & 10.00 & 8.00 & 25.37 & \\
& Mean \pm sd & $7.54 \pm 2.01$ & $6.94 \pm 1.77$ & $7.22 \pm 2.39$ & \\
& Q1 & 5.00 & 5.00 & 5.00 & 0.730 \\
& Median & 8.00 & 8.00 & 7.00 & \\
\hline
\end{tabular}

Caption: Group 1 subjects of socioeconomic status A; Group 2, subjects of socioeconomic status B1 and B2; and Group 3, subjects of socioeconomic status C1, C2, D - $\mathrm{E}^{16}$. Q1 - First quartile; Q3 - Third quartile. GIN: Gap-in-noise test; RE: right ear; LE: left year.

${ }^{*}$ Kruskal Wallis test in intergroup analysis, $p<0.05$.

\section{DISCUSSION}

Socioeconomic status may be an important variable in the reference criteria adopted in clinically used procedures. In this context, the aim of this study was to verify if the socioeconomic status influences the auditory temporal resolution measured by the RGDT and the GIN test.

There was a statistically significant difference in the performance of the RGDT between the groups according to socioeconomic status at the frequency of $500 \mathrm{~Hz}$ and in the mean of the four frequencies of the RGDT in the sample studied. By observing the mean of all groups according to the frequency tested in the RGDT, it can be seen that in all frequencies this mean was lower in Group 1 (status A), except at $1000 \mathrm{~Hz}$. This was the second frequency tested in all subjects, since the order of frequencies was maintained the same during the test application in all subjects. This aspect deserves further investigation, since the $1000 \mathrm{~Hz}$ frequency is generally considered the best frequency from the perceptual point of view, being even classically indicated to be the first frequency to be tested during the basic audiological assessment when obtaining patients' hearing thresholds in the clinical routine. It is suggested that precisely because it is a medium frequency and it is easily perceived, there was homogeneity in the RGDT results at $1000 \mathrm{~Hz}$ in all three socioeconomic status groups. Even though this influence did not occur at 2000 and $4000 \mathrm{~Hz}$, the $p$ value at $2000 \mathrm{~Hz}$ was 0.066 , showing a high tendency for significance, which was not evident at $4000 \mathrm{~Hz}$, whose $p$ value was 0.266. These particularities may have contributed to the statistical significance when observing the RGDT by the mean of the four frequencies according to socioeconomic status. These findings corroborate the literature on the influence of socioeconomic status on auditory skills ${ }^{13,14,19}$ and, in agreement with the present work, the influence of these factors in the auditory processing.

On the other hand, there were no statistically significant differences in the performance of the GIN test according to socioeconomic status, not corroborating with authors who reported a decline in these skills in individuals with more disadvantaged socioeconomic status $^{13,20}$. Moreover, during data analysis, there was no advantage of one ear over the other, agreeing with other studies that did not report perceptual asymmetry between the ears in the GIN test ${ }^{11,21-23}$, due to both ears being exposed to the same conditions ${ }^{24}$. In the GIN test, the mean performance by ear of groups 1,2 , and 3 was higher than that found in other studies with typical adults $^{5,11,12,25,26}$, being more similar to the study ${ }^{12}$ that found a GIN test mean of $6.05 \mathrm{~ms}$.

Therefore, there may or may not be a variability of socioeconomic influence according to the temporal resolution test used in the audiological clinic. Although both tests assess temporal resolution, the GIN test provides a more accurate measure of gap detection and less variability, and the RGDT reflects, at least in part, auditory fusion. Moreover, the two tests differ in other respects ${ }^{27}$, such as the presentation mode, type of stimuli, response mode, response task, total number of gap presentations, and approach to measure the shortest distance detected, which can cause differences in the performance of individuals in the tests ${ }^{7}$. Although RGDT is an easily administered test and requires less time of application and correction, counting the number of stimuli or responding verbally 
can be, from a cognitive perspective, more challenging than the response required in the GIN test ${ }^{9}$. Clinically, it could be noted that the task of the RGDT, perhaps because it presents only one item of each interval in $\mathrm{ms}$, presents higher numbers of random responses and may generate greater variability than the GIN test. The GIN test is apparently more difficult for the examiner to teach and for the subjects to understand, but after some training the responses are consistent ${ }^{28,29}$. There is the advantage that in the GIN test each interval in ms has six attempts.

Differences in neurocognitive skills influenced by the socioeconomic profile are also associated with differences in brain structure. This was presented by Noble et al. ${ }^{30}$, who studied 1,099 individuals aged 3 to 20 years whose families represented a wide range of socioeconomic backgrounds. The analyzes showed differences in the total surface area of the cerebral cortex, with more prominent differences in brain regions related to language and executive functions ${ }^{30}$. From this perspective, cognitive processes that regulate behaviors, whether of initiation or inhibition, are called executive functions. They are responsible for decision making, problem solving, and action planning and sequencing ${ }^{31}$. It is currently evident that socioeconomic status has an influence on the performance of executive function measures. It was seen that more favorable socioeconomic conditions have positive influence, while lower statuses are associated with worse performance in these measures ${ }^{32}$. The task in the RGDT is for the subject to judge if they heard one or two stimuli, as there is a decrease in the time interval between the two tones, and then signal the corresponding number of stimuli heard. This task involves cognitive mechanisms that go beyond exclusive or predominantly auditory processes ${ }^{32}$, because it involves acoustic analysis and decision power based on more elaborate conceptual mechanisms than pushing a button when hearing a silent interval ${ }^{28,29}$, as is the case with the GIN test ${ }^{9}$. There is a motor act in this task that is faster but simpler, because it does not involve judging the analysis between two response possibilities as in the RGDT test.

An important issue to be discussed is the influence not only of socioeconomic status on the sample result, but also of educational level ${ }^{19}$. However, it is known that educational indicators portray the level of socioeconomic development of a country, as access to quality education influences socioeconomic and demographic characteristics of the population ${ }^{33}$. Therefore, there is no way to exclude the educational influence on the findings of this study, since the ABEP instrument (2018) includes in its analysis the educational level of the head of household of each subject. Thus, it can be hypothesized that the most disadvantaged socioeconomic class had the worst performance on the RGDT due to low socioeconomic status associated with lowered educational level.

Another interesting aspect exposed in the literature is that the normative values of the RGDT ${ }^{12,14}$ seem to be influenced by age, as well as those of the GIN test, which also suggests such variation according to the adult and elderly age groups ${ }^{29,34}$. However, studies with the GIN test performed with typical children and adults do not present significant differences ${ }^{13,27,35}$.

The constitution of the subjects by a non-probabilistic sample and the number of subjects inserted in the same proportion in each class, in particular in statuses $A, D$, and $E$, and the age group of the sample (only young adults) are limitations of this study. Despite the possibility of bias, the study results point to an important discussion to be considered in other studies.

\section{CONCLUSIONS}

The present study points out that there is a difference in the performance of adults in the RGDT, according to their socioeconomic status. However, no statistically significant differences were found in the GIN test regarding the socioeconomic status.

\section{ACKNOWLEDGEMENTS}

The authors thank for the union and cooperativeness during the research of the Speech Therapy students of the Federal University of Rio Grande do Norte. They also thank friends, lab colleagues, and professors who referred individuals without audiological complaints to be part of this study, and those responsible for the Laboratory of Technological Innovation in Health (LAIS) of Onofre Lopes University Hospital.This study was financed, in part, by the Coordenação de Aperfeiçoamento de Pessoal de Nível Superior - Brasil (CAPES) - Finance Code 001.

\section{REFERENCES}

1. Musiek EF, Chermak GD, Bamiou DE, Shinn J. Capd: the most common "hidden hearing loss". The ASHA Leader. 2018;23(3):6-9. 
2. American Speech-Language-Hearing Association. (Central) auditory processing disorders-the role of the audiologist [Declaração de Posição]. 2005.

3. Balen AS, Santos TMM. Aspectos temporais da audição e percepção acústica da fala: revisão da literatura. In: Bevilacqua MC (org). Audiologia atual. São Paulo: Frontis; 1998. p. 57-82.

4. Musiek FE, Shinn J, Chermak GD, Bamiou DE. Perspectives on the pure-tone audiogram. $\mathrm{J} \mathrm{Am}$ Acad. Audiol. 2017;7(28):655-71.

5. Musiek FE, Shinn JB, Jirsa R, Bamiou DE, Baran JA, Zaida E. GIN (Gaps-In-Noise) test performance in subjects with confirmed central auditory nervous system involvement. Ear Hear. 2005;26(6):608-18.

6. Keith RW. Random gap detection test. St. Louis: Auditec of St Louis Ltd.; 2000.

7. Carvalho BD, Andrade KCL, Silva SG, Peixoto GO, Carnaúba ATL, Menezes PL. Comparison of two tests of auditory temporal resolution in children with central auditory processing disorder, adults with psychosis, and adult professional musicians. Distúrb. Comun. 2015;27(3):658-60.

8. Samelli AG, Schochat E. Estudo da vantagem da orelha em teste de detecção de gap. Rev. Bras. Otorrinolaringol. 2008;74(2):235-40.

9. Zaidan E, Garcia AP, Tedesco MLF, Baran JA. Desempenho de adultos jovens normais em dois testes de resolução temporal. Pró-Fono R. Atual. Cient. 2008;20(1):19-24.

10. Majak J, Zamysłowska-Szmytkeet E, Rajkowska E, Śliwińska-Kowalska M. Auditory temporal processingtests - Normative data for polish-speakingadults. Medycyna Pracy. 2015;66(2):145-52.

11. Casaprima V, Jannelli A, Lobo M, Martínez E, Lizarraga A. Obtención de valores normativos enlaevaluación de lafunción auditiva central. Rev Méd Rosario. 2013;79(2):73-7.

12. Braga BHC, Pereira LD, Dias KZ. Normality tests of temporal resolution: Random Gap Detection Test and Gaps-in-noise. Rev. CEFAC. 2015;17(3):836-46.

13. Balen SA, Boeno MRM, Liebel GA. influência do nível socioeconômico na resolução temporal em escolares. Rev. Soc. Bras. Fonoaudiol. 2010;15(1):7-13.

14. Ribas A, Vince AP, Fadel CBX, Almeida GVM. Results of a test of temporal resolution in elderly with different levels socioeconomic cultural. Global J Med. Res. 2015;15(1):29-32.
15. Kraus N, Anderson S. Low socioeconomic status linked to impaired auditory processing. Hear $\mathrm{J}$. 2015;68(5):38-40.

16. Critério Brasil (Associação Brasileira de Empresas de Pesquisa) 2015/ atualização da distribuição de classes para 2016. [atualizada em 2016 Abril 11; Acesso em 1 jun. 2017].Disponível em: http://www. abep.org/criterio-brasil.

17. Pesquisa Nacional por Amostra de Domicílios: síntese de indicadores. Rio de Janeiro. Instituto Brasileiro de Geografia e Estatística 2014 / Instituto Brasileiro de Geografia e Estatística, Coordenação de Trabalho e Rendimento. - Rio de Janeiro: IBGE. 2015 [atualizada em 2015 Set 26; acesso em 2017 Jul 01]. Disponível em: https://biblioteca.ibge.gov. br/visualizacao/livros/liv98887.pdf

18. Jeger J. Clinical experience with impedance audiometry. Arch Otolaryngol. 1970;92(4):311-24.

19. Skoe E, Krizman J, Kraus N. The impoverished brain: disparities in maternal education affect the neural response to sound. J Neurosci. 2013;33(44):17221-31.

20. Becker KT, Costa MJ, Lessa AH, Rossi AG. Teste SSW em escolares de 7 a 10 anos de dois distintos níveis socioeconômico-culturais. Arquivos Int Otorrinolaringol. 2011;15(3):338-45.

21. Weihing JA, Musiek FE, Shinn JB. The effect of presentation level on the Gaps-In-Noise (GIN) test. J Am. Acad. Audiol. 2007;18(2):141-50.

22. Balen SA, Liebel G, Boeno MRM, Mottecy CM. Resolução temporal de crianças escolares. Rev. CEFAC. 2009;11(1):52-61.

23. Musiek FE, Zaidan EP, Baran JA, Shinn JB, Jirsa RE. Assessing temporal processes in adults with LD: the GIN test. Convention of American Academy of Audiology; 2004; Salt Lake.

24. Alves WA, Rei TG, Boscolo CC, Donicht, G. The influence of musical practice in central auditory processing skills: a systematic review. Distúrb. Comum. 2018;30(2):364-75.

25. Arseno VA, Carvalho CA, Castro MP, Duarte SG, Reis ACMB, Marangoni AC et al. Comparative study of temporal resolution test results in young adults. Rev. CEFAC. 2016;18(6):1277-84.

26. Chermak GD, Lee J. Comparison of children's performance on four tests of temporal resolution. $J$ Am Acad. Audiol. 2005;16(8):554-63.

27. Iliadou VV, Bamiou D, Chermak GD, Nimatoudis I. Comparison of two tests of auditory temporal resolution in children with central auditory 
processing disorder, adults with psychosis, and adult professional musicians. Int. J. Audiol. 2014;53(8):1-7

28. Amaral MIR, Martins PMF, Colella-Santos MF. Resolução temporal: procedimentos e parâmetros de avaliação em escolares. Braz. J. Otorhinolaryngol. 2013;79(3):317-24.

29. Vellozo FF, Schwantes AL, Souza AEHS, Peixe BP, Biaggio EPV, Martins QP et al. Temporal resolution in elderly. Rev. CEFAC. 2016;18(2):355-61.

30. Noble KG, Houston SM, Brito NH, Bartsch H, Kan E, Kuperman JM et al. Family income, parental education and brain structure in children and adolescents. Nature neuroscience. 2015;18(5):773.

31. Gilbert SJ, Burgess PW. Executive function. Current Biology, [s.I.]. Elsevier BV. 2008;18(3):110-4.

32. Sbicigo JB, Abaid JLW, Dell'Aglio DD, Salles JF. Nível socioeconômico e funções executivas em crianças/ adolescentes: revisão sistemática. Arq. bras. psicol. 2013;65(1):51-69.

33. Síntese de indicadores sociais: uma análise das condições de vida da população brasileira : 2016 / IBGE, Coordenação de População e Indicadores Sociais. Estudos e pesquisas. Informação demográfica e socioeconômica, ISSN 1516-3296 ; n. 36. - Rio de Janeiro : IBGE, 2016: 146.

34. Gonsalez ECM, Alvarez LS. Os efeitos da idade no processamento auditivo temporal em adultos. Arq. Med. Hosp. Fac. Cienc. Med Santa Casa São Paulo. 2016;61(3):123-7.

35. Barreto MASC, Muniz LF, Teixeira CF. Desempenho da habilidade a resolução temporal em crianças de 07 a 13 anos. Rev Soc Bras Fonoaudiol. 2004;9(4):220-8. 